\title{
Phase Transitions Observations During the Direct Electrolysis of Ilmenite to Ferrotitanium in $\mathrm{CaCl}_{2}$ - $\mathrm{NaCl}$ Melt
}

\author{
Zhongren Zhou ${ }^{1,2}$, Yixin. Hua ${ }^{1,2, *}$, Cunying. Xu ${ }^{1,2}$, Jian. $\mathrm{Li}^{1,2}$, Yan. $\mathrm{Li}^{1,2}$, Qibo. Zhang ${ }^{1,2}$, Li. Xiong ${ }^{1,2}$, \\ Yadong. Zhang ${ }^{1,2}$ \\ ${ }^{1}$ Faculty of Metallurgical and Energy Engineering, Kunming University of Science and Technology, \\ Kunming 650093, PR China \\ ${ }^{2}$ State Key Lab of Complex Nonferrous Metal Resources Clean Utilization, Kunming 650093, PR \\ China \\ *E-mail: yxhua@kmust.edu.cn
}

doi: $10.20964 / 2016.07 .46$

Received: 18 April 2016 / Accepted: 23 May 2016 / Published: 4 June 2016

\begin{abstract}
The electrochemical reduction method is successfully used to prepare porous ferrotitanium alloys from ilmenite by using equal-molar $\mathrm{CaCl}_{2}-\mathrm{NaCl}$ eutectic as electrolyte, molybdenum rod as cathode and graphite as anode at $973 \mathrm{~K}$ with cell voltage of $3.0 \mathrm{~V}$ under inert atmosphere. The intermediate products formed in the electrochemical reduction process are analyzed by cyclic voltammetry and constant cell voltage electrolysis in the two electrodes system together with XRD, EDS analysis and SEM observation. It is demonstrated that the electrochemical reduction of ilmenite is a stepwise process since the intermediates $\mathrm{CaTiO}_{3}, \mathrm{Fe}_{2} \mathrm{Ti}$ and $\mathrm{Ti}$ are observed in the products partially reduced. In the electrochemical reduction process, the reduction of $\mathrm{FeTiO}_{3}$ firstly gives rise to the formation of $\mathrm{Fe}$ and $\mathrm{CaTiO}_{3}$ mixtures, which are formed at the interface between the ilmenite pellet and the electrolyte and are agglomerated on the surface of the samples. The intermediate $\mathrm{CaTiO}_{3}$ will be further reduced in the presence of solid Fe to form ferrotitanium alloys as well as directly deoxidized to titanium metal, which is then combined with $\mathrm{Fe}_{2} \mathrm{Ti}$ to form ferrotitanium. This reduction path is in good agreement with the cyclic voltammetry analysis. Experimental results also show that the reduced metallic grains are interconnected on the surface of the unreduced $\mathrm{CaTiO}_{3}$ particles, indicating that the metallic matrix helps the electron transfer into the oxide inside.
\end{abstract}

Keywords: Ferrotitanium, ilmenite, electrolysis, cyclic voltammetry.

\section{$\underline{\text { FULL TEXT }}$}


(C) 2016 The Authors. Published by ESG (www.electrochemsci.org). This article is an open access article distributed under the terms and conditions of the Creative Commons Attribution license (http://creativecommons.org/licenses/by/4.0/). 